\title{
Localized Parent-Child Play Therapy Interaction and Decreasing Clinical Symptoms of Attention Deficit crossuark Hyperactivity Disorder in Affected Preschool Children
}

\author{
Saeid Rahimi Pordanjani ${ }^{1}$, Bagher Ghobari Bonab ${ }^{2 *}$, Gholam Ali Afrooz ${ }^{2}$, Salar Faramrzi ${ }^{3}$
}

1. Department of Psychology and Education of Exceptional Children, Faculty of Humanities and Social Sciences, Science and Research Branch, Islamic Azad University, Tehran, Iran.

2. Department of Psychology, Faculty of Psychology \& Education, University of Tehran, Tehran, Iran.

4. Department of Psychology, Faculty of Psychology \& Education, University of Isfahan, Isfahan, Iran.

Cftent on: Rahimi Pordanjani, S., Ghobari Bonab, B., Afrooz, Gh. A., \& Faramrzi, S. (2016). Localized Parent-Child Play Therapy Interaction and Decreasing Clinical Symptoms of Attention Deficit Hyperactivity Disorder in Affected Preschool Children. Journal of Practice in Clinical Psychology, 4(3), 191-198. http://dx.crossref.org/10.15412/J.JPCP.06040307

: http://dx.crossref.org/10.15412/J.JPCP.06040307

\section{Article info:}

Received: 05 Feb. 2016

Accepted: 01 Jun. 2016

\section{Keywords:}

Play therapy, Impulsivity, Hyperactivity

\section{ABSTRACT}

Objective: Attention deficit hyperactivity disorder (ADHD) in preschoolers usually decreases their academic performance and disrupts parent-child interactions. The present study aimed at evaluating the effect of localized play therapy on preschoolers with ADHD.

Methods: The research method was quasi-experimental with a pretest-posttest design and control group. Using a multi-stage random sampling method, and considering the inclusion criteria, a total of 24 mothers of preschoolers with ADHD were selected and randomly divided into experimental and control groups. The experimental group participated in 10 sessions of localized play therapy (LPT) while the control group received no training. The instruments for data collection were Vanderbilt ADHD diagnosis parents rating scale (VADPRS) and clinical interviews. Data analysis was conducted using ANCOVA (analysis of covariance).

Results: The results showed that there was a statistically significant difference between the performance of the experimental and control groups at posttest, and upon the follow-up $(\mathrm{P}<0.05)$.

Conclusion: LPT has positive effects on clinical symptoms of ADHD in preschool children. Hence, this method can be used to improve the mental health of children with ADHD and their parents.

\section{Introduction}

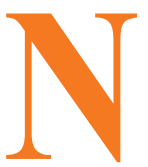

eurodevelopmental disorders have longterm and comprehensive impact on child's educational performance and lead to parenting stress (Lee et al., 2013). Regarding latest reviewed diagnostic statistic manual of mental disorders fifth edition, attention deficit hyperactivity disorder (ADHD) has a neurodevelopment pattern characterized by symptoms such as inattention, disorganization, hyperactivity, and impulsivity, often accompanied by other externalized disorders like defiant and conduct dis-

* Corresponding Author:

Bagher Ghobari Bonab, PhD

Address: Department of Psychology, Faculty of Psychology \& Education, University of Tehran, Tehran, Iran.

Tel: +98 (912) 2431503

E-mail: bghobari@ut.ac.ir 
orders. It persists until childhood and manifests in professional, educational, and social performance (American Psychological Association, 2013).

According to Barkley (2013), the prevalence of this disorder is $2 \%$ to $12 \%$ and accounts for $5 \%$ and $7 \%$ of the referrals to psychiatric centers across the globe (Barkley, 2013). About 5\% of school children suffer from ADHD, of whom $20 \%$ to $40 \%$ have learning inability and $44 \%$ suffer from at least one co-morbidity such as anxiety, depression, defiant conduct, and regression disorders (Steinberg \& Drabick 2015). Iudici and colleges found out that ADHD had a certain effect on children's performance (Steinberg \& Drabick, 2015; Iudici, Faccio, Belloni, \& Costa, 2014).

Researchers found out that ADHD would develop in the preschool period but its development and symptoms pattern would vary (Willoughby, Pek, \& Greenberg, 2012). These symptoms were investigated in the age range of 3-5 years and $8.5 \%$ of the experimental group demonstrated symptoms of severe ADHD (Mahone \& Schneider, 2012). Mahone and Schneider (2012) investigated the severity of attention challenges in preschool children and found out that children's attention deficit disorder could be challenging and observations must be planned based on children's performance and psychological tests. These children also suffer from aggression caused by sleep problems which makes mothers' rearing role more important.

ADHD is caused by a number of complex factors such as psychological and genetic mechanisms, and it influences the cognitive and behavioral performance from early childhood to adulthood (Campbell, Halperin, \& Sonuga-Barke, 2014). Furthermore, ADHD in childhood can be due to failure in response inhibition and working memory. Sjöwall, Backman, and Thorell (2015) maintained that to diagnose ADHD in preschool period, one must emphasize a variety of cognitive psychological functions (Sjöwall, Backman, \& Thorell. 2015).

Moreover, studies have shown that ADHD affects the interaction of child with parents, especially mothers. Due to defiance and disregard, these children paly less with their mothers. Also, having authoritarian parenting styles, these mothers also confront with problems such as depression, emotional problems, social isolation, shame, strictness, self-control, and self-regulation (Nikoogoftar \& Seghatoleslam, 2015).

Considering the problems of children with ADHD, early intervention and prevention of psychological damages are the priorities of rehabilitation and mental health of these children and their families. Thus, given the limited effectiveness of ADHD treatment programs, it is important to pay attention to train the parents of such children as therapists. Chronis-Tuscano and Lewis-Morrarty et al. (2014) found out that besides self-regulation problems of children, early diagnosis of ADHD can also identify the parenting depression problems and facilitate parent-child interaction (Chronis-Tuscano et al., 2014).

Developing preventive interventions for preschool children with ADHD (Halperin, Bédard, \& Curchack-Lichtin, 2012) can be used as a successful measure by taking into account the dynamic interaction model as well as environmental and biological factors in causing ADHD. Shahriyari and Hosseinifard et al. (2014) stated that in order to have proper interventions, many factors such as child-parent interaction, couple's interaction, family's public relations, child's compatibility with family, knowledge about parents should be taken into account. Parent-child interaction is based on the attachment theory and social learning, which teach parents how to make a friendly relationship with their children. Besides, parents mistreatment of children with ADHD can be reduced by educational-mental and intervention approaches (Nazemi, Mohammadkhani, $\&$ Khoshabi, 2010). Friendly guiding of mothers of children with ADHD also improves children's social performance (Lerner, Mikami, \& McLeod, 2011).

In this regard, playing creates such an atmosphere that facilitates parent-child interaction, increases the development of brain, and modifies the behavior of children with ADHD (Halperin \& Healey, 2011). Besides, playing has a significant role in the development of the nervous system and reduces child stress. Using playing and interaction with preschool children in the head start program (Bulotsky-Shearer, Bell, Romero, \& Carter, 2012) reduced the symptoms of internalizing and externalizing behavior problems and enhanced their learning ability. (Pearson, 2008) Cognitive-behavioral play intervention program increases the degree of hopefulness and social compatibility in preschool children and such group play interventions reduce children's anxiety avoidance symptoms (Nair, Yusof, \& Arumugam, 2014).

The developmental abilities and compatibility of children who had participated in the head start program and played with their peers had increased (Eggum-Wilkens et al., 2014). Using the intervention program of behavior therapy of parents of preschool children with ADHD (Huang et al., 2009) reduces parents' internalizing and externalizing behavior problems in the posttest step. 
Paying attention to native games and designing a model based on such games is regarded as a new step in behavior management of children with special needs and reducing parent's stress. These games activate the nervous system and stimulate and coordinate sensoryperceptual and decision-making parts and pave the way for sensory-motor integration. By stimulating the sensory-motor cortex, native games establish numerous links between the limbic system and optical, auditory, and verbal systems and mutually affect the brain and nervous system, enhance the quality and quantity of behavioral responses, learning, and nervous functions (Halperin \& Healey, 2011). Although Iranian native games have recently received some attention culturally and socially, their treatment and rehabilitation functions regarding children and families have been ignored.

Besides, it appears that the use of Gurney play therapy, which is based on child-parent relation therapy, which is customized for Iranian games, can be a new tackling method for this group of children. In this regard, the present study aimed to assess the effect of the localized parent-child play therapy interaction in decreasing clinical symptoms of preschool children with ADHD.

\section{Methods}

The present study used a quasi-experimental design with pretest-posttest and a control group.

The study population comprised all mothers of children with ADHD and impulsivity symptoms at the preschool centers of Isfahan, Iran, in the school year 2014-2015. The study was carried out based on the consent and cooperation of the mothers and preschool principals. Sample consisted of 24 mothers of children with ADHD. Multi-stage random sampling method was used for participants' recruitment.

After obtaining permission from the Isfahan Department of Education, 2 regions in the city were randomly selected, and out of them, 10 preschool centers were randomly selected. Based on the reports of schoolmasters, of 574 preschool children at these centers, 48 suffered from ADHD symptoms or were being treated based on psychological or psychiatric diagnosis. Afterwards, they were restrained by conducting clinical interviews with the mothers and the Vanderbilt test (parent form). Of them, 32 children displayed symptoms of weak to severe hyperactivity and attention deficit/impulsivity. Then, 24 of the mothers of the participants were randomly selected and divided into experimental and control groups after considering confidentiality and obtaining their permissions.
This form of play therapy and intervention by parents was firstly proposed by Gurney (1965). Because parents potentially have deeper emotional relations with children, this play therapy can help a parent act as a therapeutic assistant in the child's life, known as Filial therapy. As play is the best tool to facilitate positive parent-child interaction, the principles of child-centered play therapy can be used in small groups. In this program, a parent plays a role not as a therapist, but as a therapeutic agent and assistant so as to help the therapist in the process of playing the game with the child. Filial therapy has received great attention, because it prevents childhood disorders through the use of the parent-child interaction, certain games, different cultural contexts, and child-centered play therapies, as well as taking into account the principles of listening and reflection, emotional responses, medical restrictions, creating confidence in the children, etc. In this regard, given the cultural context of the Iranian community as well as simple and indigenous games, it seems necessary to provide certain treatment programs for parents of preschoolers with symptoms of ADHD.

This training package has been developed based on Filial therapy of Gurney (1965), which is based on the principles of child-centered and family-centered play therapy, customized with Iranian indigenous games. After obtaining permissions and coordination with administrators and parents, the instruments were prepared. There were 10 training sessions, each lasting 90 minutes. Participants were mothers of the children with ADHD and impulsivity, mild or severe. The researcher of the present study, as a play therapist, has re-implemented the contents of the sessions in preliminary form on a group of mothers of children with the aforementioned symptoms, according to the principles of Gurney play therapy and the mothers' experiences during the use of indigenous games. Training package validity was confirmed by professors of psychology. Each session of play therapy at home, conducted by mother and lasted 30 minutes, which was described for mothers according to the principles of child-centered play therapy. The following Table is a summary of the sessions of the customized training package (Table 1).

In this study, 2 instruments were used for data collection. Vanderbilt ADHD diagnosis parents rating scale (VADTRS) was designed on the basis of the criteria of the diagnostic and statistical manual of mental disorders fourth edition, including all 18 criteria of this disorder and consists of 47 items, which in addition to the diagnostic criteria of ADHD, also covers the criteria of oppositional defiant disorder, conduct disorder, anxiety, and depression in children. Items were scored based on a Likert-type scale. The reliability of the questionnaire, 
Table 1. Summary of the contents of the indigenous play therapy sessions

\begin{tabular}{|c|c|c|}
\hline Session & Purposes & Content and methods \\
\hline First & $\begin{array}{l}\text { Defining psychological bases of preschool } \\
\text { children with ADHD }\end{array}$ & $\begin{array}{l}\text { Questions about having children with ADHD, the challenges of family, } \\
\text { showing films of children with ADHD, evaluation of clinical symptoms }\end{array}$ \\
\hline Second & $\begin{array}{l}\text { Reviewing the homework, ways to enter the } \\
\text { child's world, describing the game room at } \\
\text { home, parent-child sessions, use of indig- } \\
\text { enous games and their effectiveness on } \\
\text { parent-child interactions }\end{array}$ & $\begin{array}{c}\text { Defining parent-child play and play therapy and its importance in pre- } \\
\text { school, showing the film of parent-child play therapy and explaining its } \\
\text { main games: (italics are transliterated from Persian) Noon Biar Kabab } \\
\text { Bebar, Gol Ya Pooch, Kaghaz Ghalam, Balloon game, the Ball and the } \\
\text { Basket, Hopscotch, Mojassame, Kalagh Par, JomJomak, Khale Bazi, Tille } \\
\text { Bazi, Gel Bazi, Moka'ab Bazi, Dooghi Masti }\end{array}$ \\
\hline Third & $\begin{array}{l}\text { Explaining the games frameworks, learning } \\
\text { the principles and skills of child-parent play } \\
\text { therapy, limits, and emotional response }\end{array}$ & $\begin{array}{l}\text { Viewing the role of parents in the way of a sympathetic response, } \\
\text { showing the film of Landreth child-centered play therapy and empha- } \\
\text { sis on its principles }\end{array}$ \\
\hline Fourth & $\begin{array}{l}\text { Checking assignments, games, improvement } \\
\text { of the child's attention and accuracy, memory, } \\
\text { parent-child interaction, decreasing the child's } \\
\text { impulsivity, active listening }\end{array}$ & $\begin{array}{l}\text { Playing the game Kaghaz Ghalam and saying a story to interact with } \\
\text { the child, JomJomak game, teaching Balloon game, playing the Ball and } \\
\text { Basket game, Noon Biar Kabab Bebar game, Gol Ya Pooch, Hopscotch }\end{array}$ \\
\hline Fifth & $\begin{array}{l}\text { Checking homework, improvement of atten- } \\
\text { tion and decision making, self-control, and } \\
\text { positive self-talk }\end{array}$ & $\begin{array}{c}\text { Mothers' reports on the games method, showing the film of the game, } \\
\text { Hopscotch, Tille Bazi, Gol Ya Pooch, the Ball and Basket game, Noon } \\
\text { Biar Kabab Bebar game }\end{array}$ \\
\hline Sixth & $\begin{array}{l}\text { Checking assignments, strengthening free- } \\
\text { dom of the child, attention skills, listening }\end{array}$ & $\begin{array}{l}\text { Evaluation of the exercises, discussion and correction of the report of } \\
\text { the recorded videos, playing the Ball and Basket game, GolYa Pooch, } \\
\text { Tille Bazi, Mojjasame game, Kalagh Par, Khale Bazi, Hide and Seek }\end{array}$ \\
\hline Seventh & $\begin{array}{l}\text { Checking assignments, understanding the } \\
\text { child's feelings of responsibility }\end{array}$ & $\begin{array}{c}\text { Evaluating mothers' reports about games and reducing parent's stress, } \\
\text { Hopscotch, the Ball and the Basket, Mojassame, GolYa Pooch, Kalagh } \\
\text { Par, Khale Bazi }\end{array}$ \\
\hline Eighth & $\begin{array}{c}\text { Checking the previous session assignments, } \\
\text { empathic understanding of the child during } \\
\text { the game, the way of interaction and facilita- } \\
\text { tion of it }\end{array}$ & $\begin{array}{l}\text { Discussions on the mothers' reports, Gol Bazi, Tille Bazi, Noon Biar } \\
\text { Kabab Bebar, the Ball and the Basket, Balloon game, Mojassame }\end{array}$ \\
\hline Ninth & $\begin{array}{l}\text { Check assignments, considering the child's } \\
\text { freedom of action, decision and response } \\
\text { inhibition, parent-child interaction style }\end{array}$ & $\begin{array}{c}\text { Evaluation of the parent's report, using games such as Hopscotch, } \\
\text { Dooghi Masti, Noon Biar Kabab Bebar, Gol Ya Pooch, the Ball and the } \\
\text { Basket, Paper Work, Mojassame, JomJomak, Gol Bazi, Toys games, } \\
\text { Hide and Seek, Balloon game }\end{array}$ \\
\hline Tenth & $\begin{array}{l}\text { Checking homework, reviewing the games } \\
\text { framework, the principles of empathy, ex- } \\
\text { pressing the boundaries, responsiveness }\end{array}$ & $\begin{array}{l}\text { Analysis of the games, according to the characteristics of the hyperac- } \\
\text { tive child and its impact on parent's stress, conclusion }\end{array}$ \\
\hline
\end{tabular}

PRACTICE in
CLINICAL PSYCH $\odot$ LOGY

based on Cronbach $\alpha$, has been reported as 0.90 for ADHD, 0.91 for OD (Oppositional Defiant), and 0.79 for anxiety and depression disorder. In this study, the reliability, based on Cronbach $\alpha$ was calculated as 0.88 for the subtest of ADHD.

The criteria of diagnostic and statistical manual of mental disorders fifth edition (Costello et al, 1982) were used for diagnostic assessment of ADHD and impulsivity symptoms of children by their mothers. These semistructured diagnostic interviews were conducted by the researcher and 2 psychologists. The validity of the interview content was confirmed by the assessor agreement.

\section{Results}

Table 2 shows the descriptive and inferential data based on the obtained data from the experimental and control groups. Since the design of this study was quasi-experimental, pretest-posttest with the control group, univariate analysis of covariance was used for data analysis to control the effect of auxiliary random variables.

According to Table 2, the experimental group in posttest and follow up has been decreased as compared with the control group.

Based on Kolmogorov-Smirnov and Levene tests, the normality assumption and establishment of variances were not significant. In other words, the KolmogorovSmirnov test results for pretest $(\mathrm{D}=0.75, \mathrm{P}=0.32$ ), posttest $(\mathrm{D}=0.06, \mathrm{P}=1.34)$, and follow up $(\mathrm{D}=0.44, \mathrm{P}=0.98)$ were not significant. The results of the Levene test for pretest $(\mathrm{F}=0.89, \mathrm{P}=0.24)$, posttest $(\mathrm{F}=1.3, \mathrm{P}=0.27)$, and follow up $(\mathrm{F}=0.28, \mathrm{P}=0.23)$ were not significant as well. Hence, this assumption was established for testing. 
Table 2. Means and standard deviations of study variable at pretest, posttest, and follow up.

\begin{tabular}{|c|c|c|c|c|}
\hline Group & Statistical index & Pretest & Posttest & Follow up \\
\hline & Mean & 31.05 & 23.9 & 24.7 \\
\hline \multirow[t]{3}{*}{ Experimental } & SD & 6.27 & 7.15 & 5.26 \\
\hline & $\mathrm{N}$ & 10 & 10 & 10 \\
\hline & Mean & 29.72 & 27.73 & 28.37 \\
\hline \multirow[t]{2}{*}{ Control } & SD & 5.36 & 4.68 & 4.97 \\
\hline & $\mathrm{N}$ & 10 & 10 & 10 \\
\hline
\end{tabular}

Table 3. The results of covariance analysis of differences of groups in Vanderbilt questionnaire.

\begin{tabular}{cccccccc}
\hline Source of change & SS & df & Ms & F & Sig. & Eta & Test power \\
\hline Group & 228.00 & 1 & 228 & 41.78 & 0.000 & 0.71 & 0.76 \\
Group (Pretest) & 716.53 & 1 & 716.53 & 131.31 & 0.80 & & \\
Error & 305.98 & 17 & 17.99 & & & \\
Total & 15283 & 20 & & & & \\
\hline
\end{tabular}

PRACTICE in CLINICAL PSYCH $Q$ LOGY

Table 4. The test results of the covariance analysis of the differences between groups with regard to Vanderbilt questionnaire scores in follow up.

\begin{tabular}{cccccccc}
\hline Source of change & SS & df & Ms & F & Sig. & Eta & Test power \\
\hline Group & 235.69 & 1 & 235.69 & 21.61 & 0.02 & 0.41 & 1 \\
Pretest & 466.03 & 1 & 466.03 & 132.11 & 0.87 & 0.14 & 0.63 \\
Error & 59.96 & 17 & 3.52 & & & & \\
Total & 1816.0 & 20 & & & & & \\
\hline
\end{tabular}

PRACTICE in CLINICAL PSYCH $\mathbb{Q}$ LOGY

Table 5. Results of covariance analysis of differences between groups in clinical symptoms of ADHD in posttest.

\begin{tabular}{cccccccc}
\hline Source of change & SS & df & Ms & F & Sig. & Eta & \multicolumn{2}{c}{ Test power } \\
\hline Group & 478.05 & 1 & 478.06 & 26.56 & 0.000 & 0.61 & 0.99 \\
Pretest & 0.017 & 1 & 0.017 & 123.43 & 0.001 & 0.97 & 0.88 \\
Error & 305.98 & 17 & 17.99 & & & & \\
Total & 3340 & 20 & & & & & \\
\hline
\end{tabular}

PRACTIEE in
CLINICAL PSYCH $\mathbb{Q}$ LOGY

Moreover, the homogeneity test of regression in the pretest and posttest $(\mathrm{F}=14.34, \mathrm{P}=0.08)$ was not significant.
As it is shown in Table 3, the effect of treatment on clinical symptoms in experimental group $\left(\mathrm{F}_{1,17}=41.78\right.$, $\mathrm{P}<0.001$ ) was significant. In other words, play therapy 
Table 6. Results of the covariance analysis test of difference of groups in clinical symptoms of hyperactivity/impulsivity in the posttest.

\begin{tabular}{cccccccc}
\hline Source of change & SS & df & Ms & F & Sig. & Eta & Test power \\
\hline Group & 191.65 & 1 & 191.65 & 25.6 & 0.01 & 0.37 & 0.96 \\
Pretest & 32.57 & 1 & 32.57 & 1.07 & 0.17 & 0.12 & 0.6 \\
Error & 512.72 & 17 & 30.12 & & & & \\
\hline Total & 32.39 & 20 & & & & PRACTICE in CINICAL PSCH L LOGY \\
\hline
\end{tabular}

training decreased the clinical symptoms of the experimental group in the posttest.

Also, significant effect of treatment on clinical symptoms in experimental group $\left(\mathrm{F}_{1,17}=21.61, \mathrm{P}<0.02\right)$ was seen at follow up (Table 4). Furthermore, there was significant effect of treatment on clinical symptoms of attention in experimental group in posttest at $\mathrm{P}<0.05\left(\mathrm{~F}_{1}\right.$, $\left.{ }_{17}=26.56, \mathrm{P}<0.001\right)$. In other words, play therapy training could increase the attention of the subjects of the experimental group in posttest (Table 5). Finally, significant effect of treatment on clinical symptoms of hyperactivity/ impulsivity in experimental group in posttest at $\mathrm{P}<0.05$ $\left(\mathrm{F}_{1,17}=6.25, \mathrm{P}<0.01\right)$ was seen. In other words, play therapy training could decrease hyperactivity and impulsivity of the subjects of the experimental group in the posttest stage (Table 6).

\section{4. .Discussion}

Early intervention programs help parents improve children's behavior. One of these interventions is playing (Gray, 2011) that is a self-selective and self-directed activity for children. Pharmacotherapy and psychological intervention reduces symptoms of ADHD. The symptoms of this disorder, in the absence of early intervention, would remain in children until adolescence and adulthood (Riddle et al., 2013).

Findings of the present study showed that participation of mothers of children with ADHD in play therapy workshops can reduce the children's symptoms. In this play therapy program, using Gurney approach (a combination of family therapy and child-centered play therapy), the researcher was not only able to enjoy the results of action research, but also study the effects of indigenous games in the form of Gurney approach (the customized play therapy training package), on the parents of ADHD preschoolers. The findings of the present study were in line with those of various related studies, including Pearson (2008), Nair, Yusof, and Arumugam (2014), Yang, Tai, Yang, and Gau (2013), Halperin, and Healey (2011), Barkley (2013), Vural, Akkaya, Küçükparlak, Ercan, and Eracar (2014), Eggum-Wilkens et al. (2014). These studies showed that play therapy increases the family's positive performance and decreases clinical symptoms of ADHD.

In support of the findings of the present study in decreasing clinical problems of children with ADHD, the research results of Pushkarna (2014), Skogan et al. (2015), Campbell et al. (2014) indicated that play therapy was effective in decreasing the symptoms of children with ADHD and increases parent-child interactions.

Therefore, a play therapy program that is customized for groups with different cultures can have better results. In this regard, by designing and customizing different models of play therapy, compatibility of parents and families increases, and the severity of the symptoms of disorders decreases. The findings showed that despite the existing restrictions on the type of parents' separation and early diagnosis of disorders during childhood, family-centered interventions, in the form of Filial therapy, have better results for parents of children with ADHD. Therefore, play therapy is in accordance with the principles of child psychology, a great experience for children, and makes new grounds for the treatment and improvement of children's problems.

The limitations of this study were the sample gender and the methods of diagnostic process. It is therefore recommended that both parents participated in the training sessions. Moreover, diagnosis must be performed by psychological experts to avoid any probable labels.

\section{Acknowledgements}

This study is a part of Saeid Rahimi Pordanjani PhD's thesis at the Faculty of Humanities and Social Sciences, Science and Research Branch, Islamic Azad University, Tehran, Iran.

\section{Conflict of Interests}

The authors declared no conflict of interests. 


\section{References}

Alavinezhad, R., Mousavi, M., \& Boojari, S. (2015). Sleep problems and aggressive behavior in children with ADHD. Journal of Practice in Clinical Psychology, 3(2), 107-12.

American Psychological Association. (2013). Diagnostic and statistical manual of mental disorders $\left(D S M-5^{\circledR}\right)$. Washington, D.C.: American Psychological Association.

Barkley, R. A. (2013). Taking charge of ADHD: The complete, authoritative guide for parents. New York: Guilford Press.

Bulotsky-Shearer, R. J., Bell, E. R., Romero, S. L., \& Carter, T. M. (2012). Preschool interactive peer play mediates problem behavior and learning for low-income children. Journal of Applied Developmental Psychology, 33(1), 53-65.

Campbell, S. B., Halperin, J. M., \& Sonuga-Barke, E. J. (2014). A developmental perspective on attention-deficit/hyperactivity disorder (ADHD). In M. Lewis \& K. D. Rudolph (Eds.), Handbook of Developmental Psychopathology (pp. 427-48). New York: Springer.

Chronis-Tuscano, A., Lewis-Morrarty, E., Woods, K. E., O'Brien K. A., Mazursky-Horowitz, H., \& Thomas, S. R. (2014). Parent-child interaction therapy with emotion coaching for preschoolers with attention-deficit/hyperactivity disorder. $\mathrm{Cog}_{-}$ nitive and Behavioral Practice, 23(1), 62-78.

Eggum-Wilkens, N. D., Fabes, R. A., Castle, S., Zhang, L., Hanish, L. D., \& Martin, C. L. (2014). Playing with others: head start children's peer play and relations with kindergarten school competence. Early Childhood Research Quarterly, 29(3), $345-56$.

Gray, P. (2011). The decline of play and the rise of psychopathology in children and adolescents. American Journal of Play, 3(4), 443-63.

Halperin, J. M., Bédard, A. C., \& Curchack-Lichtin, J. T. (2012). Preventive interventions for ADHD: a neurodevelopmental perspective. Neurotherapeutics, 9(3), 531-41.

Halperin, J. M., \& Healey, D. M. (2011). The influences of environmental enrichment, cognitive enhancement, and physical exercise on brain development: can we alter the developmental trajectory of ADHD? Neuroscience \& Biobehavioral Reviews. $35(3), 621-34$.

Huang, H. L., Lu, C. H., Tsai, H. W., Chao, C. C., Ho, T. Y., Chuang, S. F., et al. (2009). Effectiveness of behavioral parent therapy in preschool children with attention-deficit hyperactivity disorder. Kaohsiung Journal of Medical Sciences, 25(7), $357-65$.

Iudici, A., Faccio, E., Belloni, E., \& Costa, N. (2014). The use of the ADHD diagnostic label: what implications exist for children and their families? Procedia-Social and Behavioral Sciences, 122, 506-09.

Lee, P. C., Lin, K. C., Robson, D., Yang, H. J., Chen, V. C., \& Niew, W. I. (2013). Parent-child interaction of mothers with depression and their children with ADHD. Research in Developmental Disabilities, 34(1), 656-68.

Lerner, M. D., Mikami, A. Y., \& McLeod, B. D. (2011). The alliance in a friendship coaching intervention for parents of children with ADHD. Behavior Therapy, 42(3), 449-61.
Mahone, E., \& Schneider, H. (2012). Assessment of attention in preschoolers. Neuropsychology Review, 22(4), 361-83.

Nair, S. M., Yusof, N. M., \& Arumugam, L. (2014). The effects of using the play method to enhance the mastery of vocabulary among preschool children. Procedia-Social and Behavioral Sciences, 116, 3976-982.

Nazemi, F., Mohammadkhani, P., \& Khoshabi, K. (2010). Parent management training used in abusive parent-child interaction in children with ADHD. Procedia-Social and Behavioral Sciences, 5, 244-49.

Nikoogoftar, M., \& Seghatoleslam, S. (2015). The role of parenting style in predicting adolecent behavioral and emotional problems. Journal of Practice in Clinical Psychology, 3(1), 23-30.

Pearson, B. L. (2008). Effects of a cognitive behavioral play intervention on children's hope and school adjustment (PhD thesis). Cleveland: Case Western Reserve University.

Pushkarna, P. (2014). ADHD, an account of a successful play therapy (psychoanalytical psychotherapy). Apollo Medicine, 11(1), 35-36.

Riddle, M. A., Yershova, K., Lazzaretto, D., Paykina, N., Yenokyan, G., Greenhill, L., et al. (2013). The preschool attention-deficit/hyperactivity disorder treatment study (PATS) 6-year follow-up. Journal of the American Academy of Child $\mathcal{E}$ Adolescent Psychiatry, 52(3), 264-78.

Sjöwall, D., Backman, A., \& Thorell, L. B. (2015). Neuropsychological heterogeneity in preschool ADHD: investigating the interplay between cognitive, affective and motivation-based forms of regulation. Journal of Abnormal Child Psychology, $43(4), 669-80$.

Shahryari, M., Hosseinifard, S., \& Nematolahzademahani, K. (2014). Comparing early maladaptive schemas of mothers of children with attention-deficit/hyperactivity disorder, oppositional defiant disorder, and mothers of normal children. Practice in Clinical Psychology, 2(1), 74-80.

Skogan, A. H., Zeiner, P., Egeland, J., Urnes, A. G., ReichbornKjennerud, T., \& Aase, H. (2015). Parent ratings of executive function in young preschool children with symptoms of attention-deficit/-hyperactivity disorder. Behavioral and Brain Functions, 11(1), 1231-242.

Steinberg, E. A., \& Drabick, D. A. (2015). A developmental psychopathology perspective on ADHD and comorbid conditions: the role of emotion regulation. Child Psychiatry \& Human Development, 46(6), 951-66.

Vural, P., Akkaya, C., Küçükparlak, I., Ercan, I., \& Eracar, N. (2014). Psychodramatic group psychotherapy as a parental intervention in attention deficit hyperactivity disorder: a preliminary study. Arts in Psychotherapy, 41(3), 233-39.

Willoughby, M. T., Pek, J., Greenberg, M. T., \& Family Life Project Investigators. (2012). Parent-reported attention deficit/ hyperactivity symptomatology in preschool-aged children: factor structure, developmental change, and early risk factors. Journal of Abnormal Child Psychology, 40(8), 1301-312.

Yang, H. N., Tai, Y. M., Yang, L. K., \& Gau, S. S. (2013). Prediction of childhood ADHD symptoms to quality of life in young adults: adult ADHD and anxiety/depression as mediators. Research in Developmental Disabilities, 34(10), 3168-181. 


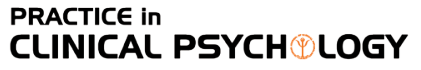

July 2016, Volume 4, Number 3

198 